\title{
Fernando Pessoa: 35 Sonetos. Versión española y prólogo de Esteban Torre. Sevilla: Renacimiento («El Clavo Ardien- do»), 2013.
}

La corriente de poesía metafísica, fuertemente arraigada en la literatura anglosajona, ha sido continua fuente de inspiración para poetas muy diversos, que han querido encuadrarse, en mayor o menor medida, en una tradición en la que la meditación y la agudeza del pensamiento, el ingenio y la concisión, la profundidad conceptual y la irisación imaginativa se unen a la hermosura de la palabra y del verso. Entre ellos, destaca el gran poeta portugués Fernando Pessoa, poeta de la desazón y de las otredades, de los heterónimos y de los desdoblamientos.

Su vertiente metafísica, clara en toda su obra, se muestra con especial interés en la poesía escrita en lengua inglesa, lengua que conocía muy bien y en la que compuso no pocos poemas. Su obra más relevante a este respecto es 35 Sonnets, publicada ahora en versión española bajo el título de 35 sonetos por la prestigiosa editorial Renacimiento de Sevilla, en una delicada y preciosa edición a cargo del profesor Esteban Torre, Catedrático Emérito de Teoría de la Literatura y Literatura Comparada.

En otras ocasiones, el profesor Torre, reconocido estudioso en diversas cuestiones de Teoría de la Literatura, como la traducción o la métrica comparada, ha traducido con rigor y con gusto poetas de la altura de Safo, Horacio, Blanco White o Verlaine. No en vano ha recibido el Primer Premio de Traducción Poética (II Certamen Nacional, Cáceres, 1988) y la Medalla de Oro con Distinción «Eduardo Benot» a la Traducción (Excmo. Ayuntamiento de Cádiz, 2012). Ya en 1988, y como homenaje a Fernando Pessoa, había publicado esta misma versión de los 
sonetos pessoanos en edición bilingüe -original inglés y versión española-, con «Nota preambular» del ilustre escritor y teórico de la literatura Vítor Manuel de Aguiar e Silva en una edición patrocinada por el Centro de Estudos Lusíadas y la Universidade do Minho de Braga, edición que venía acompañada de un extenso y profundo estudio previo, con un amplio aparato crítico en el que se tenían en cuenta aquellas variantes -anotaciones y correcciones manuscritas- del propio Pessoa sobre la primera edición de los sonetos de 1918, que se encuentran en dos ejemplares del libro conservados en la Biblioteca Nacional de Lisboa.

La versión española de la edición de 1988, completamente agotada ya hoy, es la que se reproduce en la bella edición que publica ahora Renacimiento y que constituye, sin duda, una auténtica joya literaria no sólo por el valor intrínseco de la obra del escritor portugués sino por la misma altura literaria de las traducciones. El libro se completa, además, con un prólogo del profesor Torre en el que el lector podrá encontrar las bases fundamentales de la poética pessoana, así como una exposición de los criterios y principios traductológicos que llevan al comentario y al análisis de la traducción propia. En este breve pero denso estudio preliminar se abordan tópicos, problemas y prejuicios de la crítica pessoana, revisados de modo conciso y sistemático en relación con la personalidad del autor $\mathrm{y}$, en concreto, con los sonetos ingleses. A este respecto, el profesor Torre destaca que, frente a la idea común y repetida, es un error considerar la obra inglesa de Pessoa como una mera faceta de su poesía juvenil. Bien al contrario, la lengua inglesa, la primera lengua del escritor, es utilizada por él a lo largo de toda su vida y existen en su producción inglesa auténticas cimas literarias en absoluto despreciables. Precisamente, Esteban Torre repasa la intensa actividad de Pessoa como creador y como traductor, su sólida formación de tradición anglosajona, su conocimiento profundo de la literatura y de la poesía en lengua inglesa, hechos que evidencian la relevancia que para Pessoa tuvo esta lengua. De hecho, de los 299 poemas que llegó a publicar en vida, 54 fueron redactados en inglés, nada menos que un dieciocho por ciento de su producción.

Sus años infantiles y juveniles fueron determinantes en este interés por el mundo anglosajón. Como el profesor Torre 
recuerda, Fernando Pessoa nació en Lisboa en 1888, pero, por motivos familiares, vive desde 1896 en Durban, ciudad de Natal, en Sudáfrica, por entonces parte integrante del imperio colonial inglés. Allí permanece, salvo un año, hasta mediados de 1905, y allí recibe la clásica educación inglesa. Al regresar a Lisboa, en agosto de 1905, escribe en inglés en primer lugar, y, luego, también en portugués. Es evidente que su formación inglesa será elemental para su labor creativa. Pessoa conocía bien a los autores clásicos anglosajones. Como observa Torre:

En la biblioteca de Pessoa aparecen, firmadas y anotadas por él, las obras de los poetas metafísicos John Donne y Andrew Maxwell. Asimismo, está profusamente subrayado un ensayo de Francis Thompson sobre Shelley -al que se relaciona también con los poetas metafísicos-; y las obras del propio Shelley, The Complete Poetical Works, están firmadas con el nombre de Alexandre Search, el primer seudónimo o heterónimo de Fernando Pessoa. (pp. 16-17)

La presencia de Alexandre Search como personaje que firma los poemas juveniles, seudónimo de Pessoa, es tratada en el prólogo en relación a la conocida heteronimia pessoana, vinculándola a la teoría literaria del escritor portugués.

Cuando Fernando Pessoa publica sus primeros libros en verso, en 1918, 35 Sonnets y Antinous, ya es, como se indica en el prólogo, un poeta completamente maduro: tiene treinta años y sus ideas sobre la despersonalización en la poesía están completamente definidas. Poco después, en 1921, con 33 años, publica English Poems I-II, con una nueva versión de Antinous, y English Poems III, con un único poema titulado Epithalamium. Estos libros habrían sido completados con otros volúmenes más que contendrían la reedición de los sonetos revisada según las enmiendas realizadas por Pessoa y hoy conservadas en la Biblioteca Nacional de Lisboa. Las correcciones y anotaciones manuscritas sobre los sonetos sugieren, de acuerdo con Esteban Torre, que el poeta portugués tenía el propósito de reeditar los sonetos y, probablemente, de ampliarlos a cincuenta, con lo que el título definitivo sería el de Fifty Sonnets. No obstante, esta reedición finalmente no llegó a aparecer. Por tanto, los sonetos 
editados hoy en Renacimiento son aquellos 35 Sonnets redactados entre 1908 y 1914 y publicados en 1918, aunque con las enmiendas manuscritas que Pessoa realizara en los ejemplares depositados en la Biblioteca Nacional de Lisboa.

En la prensa anglosajona que se hizo eco de los sonetos tras la publicación en 1918 -The Times, The Glasgow Herald-, las reseñas y comentarios destacan el gran conocimiento del inglés isabelino y su afinidad con el estilo de Shakespeare y los poetas filósofos de la época, no solo por los temas elegidos -la vida y la muerte, la apariencia y la realidad-, sino por los juegos retóricos y la complicación estilística, valorados éstos por sí mismos y por estar al servicio del sentido textual. Como indica perspicazmente Torre, los críticos anglosajones, que relacionaban el estilo de Pessoa con Shakespeare y con los poetas filósofos, no estaban equivocados en sus apreciaciones y relaciones con los poetas indicados, aunque habría que añadir una segunda vinculación que iría más allá de la «orientación sintética y unificadora de estos poetas»: la de los metafísicos posteriores del siglo XVII, cuyo espíritu sería, frente a los poetas filósofos anteriores, de carácter «analítico y disgregador» (p. 24). En este sentido, sería John Donne el más claro exponente de entre estos autores metafísicos, con un lenguaje igualmente cercano al estilo shakespeareano, al que suma una intensa fuerza dramática. Esta línea poética de reflexión y despersonalización de índole dramática interesó, sin duda, a un escritor como Pessoa, cuya visión sobre la literatura exigía precisamente una continua objetivación progresiva del sujeto: «Es lo que preconizaba Fernando Pessoa: ir subiendo peldaños a través del esfuerzo reflexivo en la "escala de la despersonalización", hasta llegar a ser "un poeta que es varios poetas, un poeta dramático escribiendo poesía lírica"» (p. 25 ). Junto con estas influencias, menciona Torre otras fuentes más cercanas en el tiempo a Pessoa: los estudios psicológicos de William James y, sobre todo, el Essai sur les donnés immédiates de la conscience, de Henri Bergson (p. 39).

Los 35 Sonnets sería, según Esteban Torre, no sólo «lo mejor y lo más representativo de la obra inglesa» del escritor portugués, sino «la expresión más acabada de su espíritu analítico, penetrante y sagaz (p. 25). Descarta, pues, su traductor la falsa 
idea de que se trata de una obra secundaria de juventud para afirmar su indiscutible valor literario dentro de la obra completa de Pessoa y dentro de la poesía occidental:

Escritos, en efecto, en un inglés sorprendente -enigmático, arcaizante, oracular a veces; pero lúcido siempre, preciso y justo-, sirven de cauce a uno de los torrentes poéticos más poderosos de toda la literatura europea. Son treinta y cinco diamantes del lenguaje, tallados con tan exacta maestría, que las aristas de los sonidos y las facetas de las ideas vienen a constituir una misma y perfecta estructura. (p. 25)

Los sonetos ingleses habían sido traducidos, total o parcialmente, al portugués en varias ocasiones: en 1954 por Adolfo Casais Monteiro y Jorge da Sena (Alguns dos «35 Sonetos» de Fernando Pessoa), aunque los traductores no respetan, salvo en algún caso, en su versión de los catorce textos elegidos los moldes métricos del original y prescinden de la rima. Finalmente, la traducción completa se hará en 1974 con la publicación de los Poemas Ingleses, editados por Jorge de Sena y cuya reimpresión se haría en 1982. La dificultad de traducir el verso inglés al portugués es destacada por estos y otros traductores al comentar que la traducción del verso en portugués requiere $-\mathrm{y}$ lo mismo sucede en español-más sílabas que el verso inglés original. Esto explica que el decasílabo -lo que en la métrica española llamaríamos endecasílabo - se traduzca, en casos como el de Pessoa, por un verso alejandrino que permite una mayor extensión en sílabas y en palabras. Esta propuesta en la traducción del metro - del decasílabo, o endecasílabo, al alejandrino- es seguida, en general, por otros traductores portugueses posteriores. En 1975 Fernando Dias traduce los sonetos utilizando, sin embargo el verso endecasílabo, acorde con el modelo del original inglés, aunque prescinde de la rima. Se trata, por tanto de endecasílabos blancos. No obstante, como indica Esteban Torre, el traductor no acierta cuando introduce de forma ocasional alguna rima consonante o asonante. En algunas traducciones hechas al español sucede algo similar. Los versos se traducen sin rima o la medida no se ajusta a la del endecasílabo propio del soneto clásico.

A nadie escapa la dificultad de traducción de la poesía, especialmente por las complicaciones que implica la búsqueda de 
equivalencias rítmicas y sonoras. Con esta obra de Fernando Pessoa a las dificultades habituales de la traducción del verso se suman las de un estilo especialmente intrincado. A pesar de estos claros y arduos impedimentos, el lector de los sonetos en la versión española de Esteban Torre editada en Renacimiento encontrará auténticos sonetos, auténticos versos, auténtica poesía. Encontrará igualmente una recreación precisa y bella del estilo del original.

De acuerdo con las ideas que expresa en su Teoría de la traducción literaria (Síntesis: Madrid, 1994), Esteban Torre consigue en sus traducciones crear un texto en que la traducción, el texto traducido, es realmente una composición nueva que se sustenta artísticamente por sí sola. Es así como la traducción poética se concibe en el terreno legítimo de la creación literaria: «no sería más que una forma de creación literaria, que consistiría en recrear en otra lengua una obra ya existente en una lengua dada» (p. 160). El traductor de poesía debe ser entonces poeta para recrear y reproducir, traducir o trasvasar a la lengua propia los juegos de sonidos, el ritmo y la rima, los recursos estilísticos. El traductor poeta atiende no sólo, como indica Torre, a la semántica textual, a la forma del contenido, sino también, como fundamento estético del texto, a la forma de la expresión. Ambas formas, forma del contenido y forma de la expresión, han de adaptarse a la lengua a la que se traduce. De ese modo, se es realmente fiel a la literalidad y al espíritu del texto original.

En el prólogo a los 35 Sonetos se plantean precisamente y en esta misma línea algunos problemas respecto a la traducción de los sonetos pessoanos. El criterio más importante con el que se compromete el traductor es el de la fidelidad al texto fuente. El profesor Torre tiene una larga experiencia en traducir el verso siguiendo la premisa de ser lo más literal que sea posible sin traicionar la personalidad y el carácter del original. En estas traducciones el lector puede comprobar, si va al texto inglés, que está ante una traducción realmente soberbia, pues en ella se logra aunar literalidad y hermosura, fidelidad y belleza. En efecto, el criterio de que la traducción sea natural se cumple a la perfección. El lector tiene la completa sensación de estar ante poemas escritos en su lengua. La fidelidad no solo se refiere, como bien 
señala el profesor Torre, al sentido, a la letra, sino a la estructura métrica, estilística y espiritual de los poemas de Pessoa. A este respecto, se podrá comprobar que se respeta la medida original, traduciendo en verdaderos endecasílabos, con ritmo y con rima. Todos los poemas sin excepción están escritos con versos endecasílabos. Aunque el alejandrino habría permitido un mayor número de sílabas, el traductor ha preferido ser fiel a Pessoa y usar el verso endecasílabo para buscar y acomodarse precisamente a la sonoridad original, «a la clásica majestuosidad del soneto pessoano y del soneto español». Emplear el verso alejandrino hubiera supuesto una traición a la lógica poética que rige los textos originales. Igualmente, siguiendo el modelo del soneto, el traductor mantiene la rima consonante en todos los poemas, siendo, así, igualmente fiel a los textos pessoanos y a la misma tradición del soneto. Conviene matizar que la rima en los textos traducidos funciona de modo equivalente a la rima de los textos originales, pues se corresponde y se complementa con el sentido total del conjunto y con los juegos de contrastes y oposiciones de índole metafísica y reflexiva tan del gusto de Pessoa. Resulta verdaderamente admirable comprobar con qué naturalidad el verso español rimado en esta versión recoge las ideas y el estilo del gran escritor portugués para ofrecer al lector un poema auténtico y sin fisuras.

El soneto de Pessoa sigue el modelo inglés shakespeareano con pareado final, con rimas del tipo ABAB CDCD EFEF GG, modelo ajeno a la tradición poética española, que evita el pareado. Solamente algunos poetas modernos, como Jorge Luis Borges, que, formados también en la cultura anglosajona, han querido rendir homenaje a la tradición inglesa, han usado con cierta asiduidad este final de rima pareada para el soneto. Aquí el traductor introduce, con buen criterio, una variación en el esquema de las rimas, evitando, en consonancia con la tradición española, el pareado final en aras de «eludir el latiguillo acústico» (p. 29) y de dar mayor naturalidad y fluidez al soneto en el marco de la poesía hispánica. El modelo de rima podría, pues, variarse del siguiente modo: ABAB CDCD EFG EFG. Las razones de esta variación, para el profesor Torre, obedecen a la necesidad de respetar la lengua y la cultura a la que se traduce: «Una vez 
decidido este cambio -que estimo absolutamente necesario, ya que las convenciones métricas son inseparables del espíritu de la lengua a la que se traduce-, lo he mantenido en todos los sonetos» (p. 29).

En el prólogo a la edición, señala Esteban Torre algún caso de rima asonante del original de 1918 -soneto I y soneto XIV-, corregido por el mismo Pessoa, y otro caso de rima con palabra repetida-soneto XXXIII-, igualmente corregido por el autor en las anotaciones manuscritas. El escrúpulo del poeta portugués al revisar estos detalles, realmente nimios en el conjunto de los sonetos, demuestra hasta qué extremo daba importancia a la forma poética. Sabedor de esta atención y de este rigor expresivo pessoanos, Esteban Torre no deja a un lado tampoco la traducción de la forma, esencial en poesía:

Prescindir de los aspectos formales sería la peor de cuantas infidelidades pudieran cometerse al traducir los 35 Sonnets. Así pues, he procurado reproducir el ritmo, la sintaxis, la música de los versos de Fernando Pessoa, tanto como el contenido de las palabras aisladas. (p. 30)

Este propósito se lleva realmente a cabo en la versión española. A veces la traducción es de una literalidad asombrosa, sobre todo teniendo en cuenta las diferencias entre la lengua inglesa, mucho más sintética en la expresión, y la española que requiere, como ya se ha mencionado antes, más sílabas $\mathrm{y}$, en consecuencia, más palabras para expresar las mismas ideas. Véase este ejemplo tomado del soneto XVIII, que el propio Torre cita en su prólogo:

Mi amor, no yo, mi amor es egoísta;

mi amor por ti se quiere más que a ti...

My love, and not I, is the egoist.

My love for thee loves itself more than thee...

O este otro verso, también citado por el traductor, del soneto XXXIV: 
Dichoso el manco, el cojo, el loco, el ciego...

Happy the maimed, the halt, the mad, the blind

En realidad, los ejemplos de literalidad podrían multiplicarse. Veamos otro más en el prodigioso soneto I, del que se cita aquí el primer cuarteto. Junto a la equivalencia de los moldes métricos, el profesor Torre consigue recrear el estilo y la retórica concentrada del escritor, utilizando palabras y conceptos esenciales en el juego poético:

Ni al hablar o escribir, ni en la mirada nos mostramos jamás: nuestra conciencia ni en voz ni en libro puede ser cifrada. Revelamos tan solo una apariencia.

La traducción es reflejo claro del serventesio original inglés, en el que el concepto es exactamente el mismo, al tiempo que la sintaxis y el ritmo versal encabalgado son prácticamente idénticos:

Whether we write or speak or do but look We are ever unapparent. What we are Cannot be transfused into word or book. Our soul from us is infinitely far.

El último verso, el menos literal de los cuatro, no desdice de la idea real que se quiere transmitir y, en el conjunto del cuarteto y del soneto en su totalidad, se ajusta perfectamente al sentido de la imposibilidad de la comunicación del ser por el lenguaje.

La complicación retórica basada en la repetición también es traducida por el escritor, casi literalmente en muchos casos. En esta línea, los finales de los poemas son especialmente importantes por su carácter definitivo de la meditación o la discusión previa. En este mismo soneto primero, la traducción se ciñe igualmente a la concisión conclusiva en un estilo que reproduce el del original en la reiteración espejeada de las palabras y de los seres:

Somos sueños del propio entendimiento, y sueños de otros sueños de los otros. 
We are our dreams of ourselves' souls by gleams, And each to each other dreams of others' dreams.

Véase también la excelente traducción del cierre del soneto IX, cuyos versos citados no son sino hermanos en belleza y acierto de los originales:

Vivo yo, así, el morir de cada día, pensando en un pensar hacer mañana.

Hence live I the dead life each day doth bring, Repurposed for next day's repurposing.

El traductor, como el poeta, muestra, por otro lado, un pleno conocimiento de la tradición poética. La traducción española, como el original inglés, con ecos de la tradición metafísica, ofrece no solamente una recreación pessoana de excelente e indudable calidad, sino que lo hace con el recuerdo de la propia tradición española, de la mejor tradición española, con huellas de Lope o de Quevedo, de aquellos poetas que, como Pessoa o Shakespeare, hicieron suya la tradición europea del soneto filosófico, metafísico, conceptual, barroco.

En aquellas ocasiones en que el traductor se ha visto obligado a hacer alguna modificación, su premisa ha sido siempre respetar el espíritu del original. Así, como él mismo indica en el prólogo, ha preferido «recrear una imagen, alterar un fragmento, añadir una leve pincelada, cuando la estructura del poema así lo requería» a favor del buen sentido poético. Es lo que sucede, por ejemplo, en estos versos del soneto XIV:

$\mathrm{Al}$ ocaso nacemos, y morimos antes del alba. Sólo sombras vemos.

Nunca luz y color: sólo racimos

de la tristeza de los crisantemos.

We are born at sunset and we die ere morn, And the whole darkness of the world we know. How can we guess its truth, to darkness born, The obscure consequence of absent glow? 
Aunque los crisantemos no aparecen en el soneto original, la oscuridad (darkness, obscure) y la ausencia de brillo y de color (absent glow) quedarían simbolizadas en el último verso en la versión española en que se menciona la tristeza de los crisantemos.

Por otra parte, los sonetos, como indica el traductor en el prólogo, forman un todo organizado y estructurado en el libro, en un desarrollo temático con principio y final. En el breve y condensado estudio que de ellos se hace, se destacan algunas claves que sirven de base a la interpretación de los mismos: desde el primer soneto aparece la idea principal que se ve reiterada en el libro: la de la incomunicabilidad de los seres humanos. El hombre que se enfrenta a la vida se sitúa siempre en un abismo infranqueable, frente a un mundo de sueños o de sombras que el pensamiento no logra nunca descifrar, como tampoco puede el hombre conocerse a sí mismo, ni a los demás, por el pensamiento:

La incomunicabilidad es absoluta. La cara del alma está encerrada tras una máscara, y debajo de la máscara hay otra máscara, y aun ésta se encuentra a su vez enmascarada. El mismo pensamiento, cuando intenta vislumbrar el verdadero rostro del alma, va cubierto por un antifaz. (p. 38)

La superposición de planos que revelan la dificultad de llegar a un núcleo verdadero se expresa por el juego estilístico de las palabras que el traductor recrea también en la versión española:

Un sinfín de caretas y antifaces enmascara la faz del alma; y, cuando -por diversión- se quita los disfraces, ¿sabes si es ella lo que estás mirando?

La verdadera máscara no siente nada bajo ella misma, y se disfraza. Por más que sea el comenzar consciente, la somnolencia crece y atenaza.

Entre espejos vivimos, aterrados por nuestras propias muecas, como niños; y si, al azar, pensamos por momentos 
ver la cara del alma, enmascarados por detrás de su máscara, hacen guiños los mascarones de los pensamientos.

La consciencia de la separación, de la otredad continua, viene a explicar, en última instancia, toda la diversidad temática de Pessoa y su concepción del hombre y del poeta como figura de sombras y de vacío. La forma del soneto y el estilo complejo de la poesía metafísica eran cauces idóneos para la expresión de este conjunto de motivos recurrentes. El logro, y máximo valor de esta bella edición de los 35 Sonetos, ha sido precisamente, como indica el profesor Torre, ofrecer al buen lector de poesía auténticos sonetos fieles a la lengua española y fieles al carácter y al estilo de Fernando Pessoa:

He querido ofrecer, en definitiva, una serie de treinta y cinco sonetos -que, en verdad, contienen in nuce todo el drama pessoano: la dialéctica del sueño y la realidad, del pensamiento y la acción, del pensar y el ver; o la vida como sueño, el misterio del mundo, las máscaras del alma- para que puedan ser recibidos por el lector español, no como traducciones de una lengua extranjera, sino como si primitivamente hubieran sido escritos en la lengua española. (p. 34)

María Victoria Utrera TORREMOChA Universidad de Sevilla 